\title{
Understanding the interaction between actors in the product-service system development
}

\author{
Lílian Salgueiro Azevedo ${ }^{a}$, José Carlos de Toledob, Mario Orestes Aguirre González \\ aPrograma de Pós-graduação em Engenharia de Produção, Universidade Federal de São Carlos - UFSCar \\ bDepartamento de Engenharia de Produção, Universidade Federal de São Carlos - UFSCar \\ 'Departamento de Engenharia de Produção, Universidade Federal do Rio Grande do Norte - UFRN \\ e-mails: liliansaazevedo@gmail.com; toledo@dep.ufscar.br; mario@ct.ufrn.br
}

\begin{abstract}
The objective of this paper is to understand the interaction flow between actors from a customer company and with external actors, mainly with the provider company, when developing a Product-Service System offering. This understanding is useful for companies, because it allows them to identify and analyse how these interactions are managed and transformed into PSS requirements that can be used for designing and developing a PSS. A review of the mapping methods was done, and the Actor's and System Maps showed to be the most appropriate, since they have a clear PSS perspective. The research method used in this research was the case study and the semi-structured interview was used for data collect. The study was developed through the case study of a telecom company, which buys a PSS offering. The conclusion is that after creating the categories for the information flows, it was possible to analyse the information and to identify, e.g. omitted information and non-optimal distance between actors, which can affect the PSS development.
\end{abstract}

Keywords: Product-service system, PSS, product-service system development, information flow, Actor's Map.

\section{Introduction}

Traditionally, manufacturing companies have concentrated on the design, development and production of physical products. Nowadays, global competition, outsourcing practices, environmental legislation, and commitments on the product recommend that companies take greater responsibilities for their products, making some manufacturers change their business strategies: selling a service rather than a physical product. Instead of the product itself, the service and knowledge associated with the use of the product are perceived to be of greater value to customers. In the academic community this shift in focus from product-oriented to service-oriented has been called Product-Service System (PSS) (TAN, 2010).

The business interests are the main drivers for a change in the business environment from selling products to providing Product-Service Systems (KIMITA et al., 2015; SONG et al., 2015; WEEKS; BENADE, 2014; ZINE et al., 2014). Increased competitiveness, cost reduction, greater convenience and flexibility for the client, and better corporate identity (BEUREN; GOMES FERREIRA; CAUCHICK MIGUEL, 2013) are some of the factors that drive PSS.
According to Vasantha et al. (2012) and Mont (2002), integration and collaboration between actors in a PSS offering have been considered as important aspects of creating a successful PSS. Aurich, Fuchs and Wagenknecht (2006) recognize that these actors need to have a common understanding and vision of the entire PSS offering. Lindahl, Sakao and Carlsson (2014) emphasize that in many cases, in order to be able to develop and improve the PSS delivery, the actors from customer and from supplier must have access to relevant information, need to know how this information is transferred and need to have an idea of who will use the information they possess. Therefore, it is advantageous for companies to identify the role of these actors, especially due to the increase in the variety and complexity of customer requirements, legislation and competition.

When a customer company purchases a PSS offering, this company and its supplier begin to have a closer contact during the use phase. As a result, the dialogue between them tends to increase, being an important source of information, for example on how to improve the development or how to customize the PSS offering, in order to improve the value received by the customer (LINDAHL; SAKAO; ÖHRWALL RÖNNBÄCK, 2009). It is important to have 
a good knowledge of the transmitters and receivers to make the information useful, therefore, the information can be used properly (LINDAHL; SAKAO; CARLSSON, 2014).

The objective of this paper is to understand the interaction flow between actors from a customer company and with external actors, mainly with the provider company, when developing a Product-Service System offering. This understanding is useful for companies, because it allows them to identify and analyse how these interactions, which are related to PSS offering, are managed and transformed into PSS requirements that can be used for designing and developing a PSS.

The paper is structured as follows. After this introduction, Section 2 covers the Theoretical background that is introducing the mapping methods and presenting the one used in this study. The subsequent section describes the Research method employed. Section 4 presents the Case study and the results of the research, which is followed by the Discussion in Section 5. After the following discussion, some concluding remarks and future research are presented.

\section{Theoretical background}

\subsection{Mapping methods}

According to Tan (2010) rarely just one party delivers services and products, but frequently request a network of actors to provide them. Tan (2010) and Lindahl, Sakao and Carlsson (2014) explain that an actor can be an individual, group or organization, which are engaged in the business between a supplier and a customer. According to Tan (2010), to understand how actors are interacting, it is important to map them and their relations, creating an overview of how they are organized, which enable to better recognize the motivations and to understand the requirements of the each one.

In the literature, there are many mapping methods, e.g., Customer Value Chain Analysis (CVCA) (DONALDSON; ISHII; SHEPPARD, 2006), Environmental Value Chain Analysis (EVCA) (ROSE; STEVELS, 2000), System Organization Map (MANZINI; COLLINA; EVANS, 2004), Activity Modelling Cycle (AMC) (MATZEN, 2009), Service Ecology Map (MORITZ, 2005) and Actor's and System Maps (LINDAHL; SAKAO; CARLSSON, 2014).

After reviewing these methods, the conclusion was that the Actor's and System Maps are the most appropriate methods to use in this study since they have a clear PSS perspective, that cover actors, products, services, information, and activities, and they are easy for users to understand and use, and easy to communicate, e.g., high level of visualization.

\subsection{Actor's Map}

According to Lindahl, Sakao and Carlsson (2014) the aim of the Actor's Map is to provide a clear overview of the actors involved in a PSS offering, thus this map is a support to identify the important actors and their involvements and requirements. The Actor's Map also support the identification of non-optimal distances between actors, e.g., if there are many actors involved to transfer an information, which can be lost, filtered or change along the way, because the distance between the first actor to the last one is excessively long. To distinguish between different types of actors, e.g. actors related to the customer, a color-coding of the boxes could be used.

The first task when creating an Actor's Map is to identify relevant actors doing an interview with the actors themselves, asking them their perspective of how the PSS offering is received, asking them to draw the Actor's Map. It is quite common that different interviewees have different views; hence, there is a risk of not making the map in detail, since relevant actors and their interactions can be not visible in a more aggregated overview (LINDAHL; SAKAO; CARLSSON, 2014).

The Actor's Map also illustrates the types of interactions, which includes flows and direction of each interaction that can be, e.g., products, services and information, between different actors. The information is usually divided into two types, 1 st and 2nd level information. First level information is directly related to the PSS offering and the ability to provide it. Second level information is indirectly related to the PSS offering and is e.g. about how to provide the PSS offering process and future PSS offerings (LINDAHL; SAKAO; CARLSSON, 2014).

\subsection{System Map}

System Map visualizes in more detail the types of interaction of products, service, and information, as well as the activities available to obtain interactions. An activity is the condition in which things are happening or being done and includes, e.g., support systems, tools, methods and processes. The System Map also allows identifying the information flow in the system. Different life cycle phases of the PSS offering imply different activities that can be illustrated (LINDAHL; SAKAO; CARLSSON, 2014).

\section{Research method}

The research method used in this qualitative research was the case study and the semi-structured interview was used for data collect. During the interviews the mapping method Actor's and System Maps were used and since the respondents possessed limited background knowledge about this mapping method, semi-structured interviews were the more suitable, according to Lindahl, Sakao and Carlsson (2014). Bryman and Bell (2007) explain that the semi-structured interviews are one of the most important data gathering tools and the most common method used in qualitative research. In order to reach the objective of this research, the way to understand the complexity of the 
interactions between the actors was to interview the actors themselves.

During the interviews, it was important that the interviewer and respondent had direct contact allowing the interview to be more comfortable for both and because the interviewer must need to see the map being drawn by the respondent. For that reason, face-to-face interviews and interviews via video conference were performed. The face-to-face interviews took place in the respondents' office and the interviews via video conference was necessary since or the respondents worked in another country or did not work in the same city where the face-to-face interviews had been performed. Then the best solution was conducting the interviews via video conference, and due to the time and budget did not allow the interviewer traveling.

The case study protocol guide, the respondents' selection, the interviews transcription, analysis, verification and interpretation of the collected data, followed the steps of the interview process proposed by Brinkmann and Kvale (2015). To obtain theoretical knowledge regarding the PSS offering, the company's website was examined.

To validate case study protocol guide, a face-to-face semi-structured interview was conducted with an employee, who was the first contact to answer the interview request sent by email. During this interview, the interviewee suggested four possible respondents, who, due to their position in the company and their involvement with the PSS offering, were the first to be interviewed. Thereby, the selection of the last four respondents followed Babbie's (2013) recommendation, which explains that instead of deciding in advance who will be interviewed, the researcher selects them gradually by asking the respondents to suggest who can be the next interviewee. Then, in total, eight employees were individually interviewed, four face-to-face interviews and four via video conference. Although, there were no time constraints, the interviews took between 40 minutes and 1 hour to complete (Table 1). To prepare the interviews for analysis, all were recorded, with permission of the respondents, and then transcribed.

In this study, the participants were asked the same questions to be able to compare the answers of each one. Each interview differs from one another, since it depends on the respondents' point of view about the PSS offering. Thereby, the order of questions asked can differ for each interview, but in all of them, the relevant topics were covered. Conducting interviews with different people from different departments of the company was necessary for having a broader view of the connections between actors, thereby, having a more complete Actor's and System Maps.

The most common form of analysis and used in this study is content analysis, which consists of a detailed reading of all interviews transcripts, identifying words
Table 1. Respondents within customer company.

\begin{tabular}{|c|c|c|}
\hline Working Position & $\begin{array}{c}\text { Interview } \\
\text { duration (min) }\end{array}$ & Mode \\
\hline Global Technical Project Manager & 42 & $\begin{array}{c}\text { Face to } \\
\text { face }\end{array}$ \\
\hline Product Manager & 49 & $\begin{array}{c}\text { Face to } \\
\text { face }\end{array}$ \\
\hline Product Marketing M2M Director & 38 & $\begin{array}{c}\text { Face to } \\
\text { face }\end{array}$ \\
\hline Vice President Global M2M & 47 & $\begin{array}{c}\text { Face to } \\
\text { face }\end{array}$ \\
\hline Product Marketing Manager & 46 & $\begin{array}{c}\text { Video } \\
\text { conference }\end{array}$ \\
\hline Video \\
conference \\
Roaming Director & 42 & $\begin{array}{c}\text { Video } \\
\text { conference } \\
\text { Video } \\
\text { conference }\end{array}$ \\
\hline M2M International Presales \\
Expert & 45 & \\
\hline
\end{tabular}

and groups of words that make sense for the search, as well as classification in categories or themes that have similarities (BRINKMANN; KVALE, 2015). To determine the reliability and validity of the information gained, more than one respondent were interviewed, as explained above, and the result was compared with one another combined with the theoretical knowledge obtained from the PSS offering. Since much of the data collected are sensitive or confidential, it was decided do not describe detailed data of the participating company' processes.

\section{Case study}

\subsection{Background}

The research was conducted on a case study of a French telecom company in order to address the customer's perspective of a PSS offering. This company works in partnership with others multinational companies from the same branch of business. In order to enrich its machine-to-machine (M2M) products and solutions portfolio to meet mainly their customers' international roaming needs, these partner companies had agreed to work in collaboration with a Swedish telecom company, which provides a PSS offering to support these needs. This offer is a cloud connectivity platform between M2M devices.

All of these companies (customers and supplier) work together to develop and enhance this PSS offering. This platform is owned by the supplier, which provides only the service to customers. The challenge of this collaboration lies in the fact that this PSS is a shared offering, this new way of working involves many actors, and there is a need of meaningful changes in corporate culture and in the relationships between internal and external actors as well. 


\subsection{Actor's Map}

The Actor's Map below, Figure 1, provides an overview of the actors involved in the PSS offering of the case study, showing their main connections and assignments. Examples of actors from customer company are: Marketing Department, Product Director, Project Manager, and Technical Department. Examples of actors from provider company are: Sales Department and Project Manager. The map also involves actors that traditionally may be considered out of the PSS offering, e.g., Roaming Operators and Consulting Firms. The actors are represented by blue boxes and the interactions, by arrows. The actors that are mentioned as a group of several actors are encircled in different colours. The full list of the actors and their main assignments is not presenting in this paper since it is confidential.

\subsection{System Map}

The System Map below, Figure 2, provides a more detailed perspective of what kind of information is transferred between the actors within the PSS offering. Differently from the method used, it was decided to present the information levels on System Map, because during the interviews the respondents had difficulty in identifying the levels. Thus, during the data analysis the interviewer analysed all the interactions identifying the levels of each information. The red line illustrates the 1th level of information and the blue line the 2nd level. 1th level of information describes main information regarding a specific PSS offering. 2nd level of information describes main information aimed for developing future potential offerings. All connections were numbered in order to facilitate what each information transferred implies and each number is presented with an explanation. However, the list of the information is not presenting in this paper since it is confidential. The System Map from customer company's point of view supports the identification of information flow between the actors, being possible to identify if any information is lost, filtered or changed along the way.

\subsection{Information flows}

As it can be noted, the interactions found out during the interviews were only the information transferred between the actors. Since the analysis of information flow was complicated to be done, it was necessary to classify each information by categories. Therefore, after the interaction has been identified as first level or second level, it was needed go back in each interaction, which were numbered, identifying similar information and, then, separating them

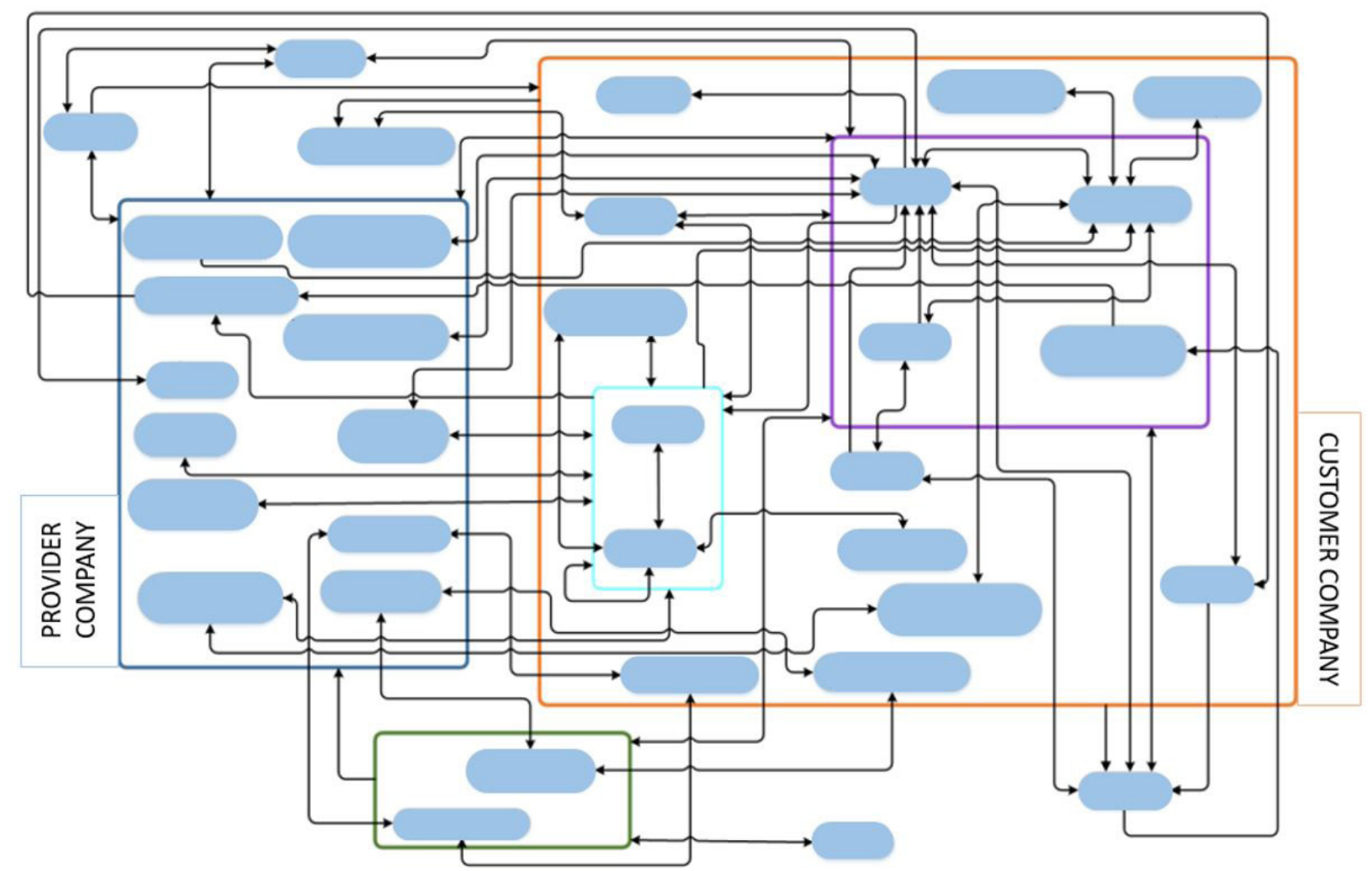

Figure 1. The Actors Map illustrates the participating actors and their connections. 


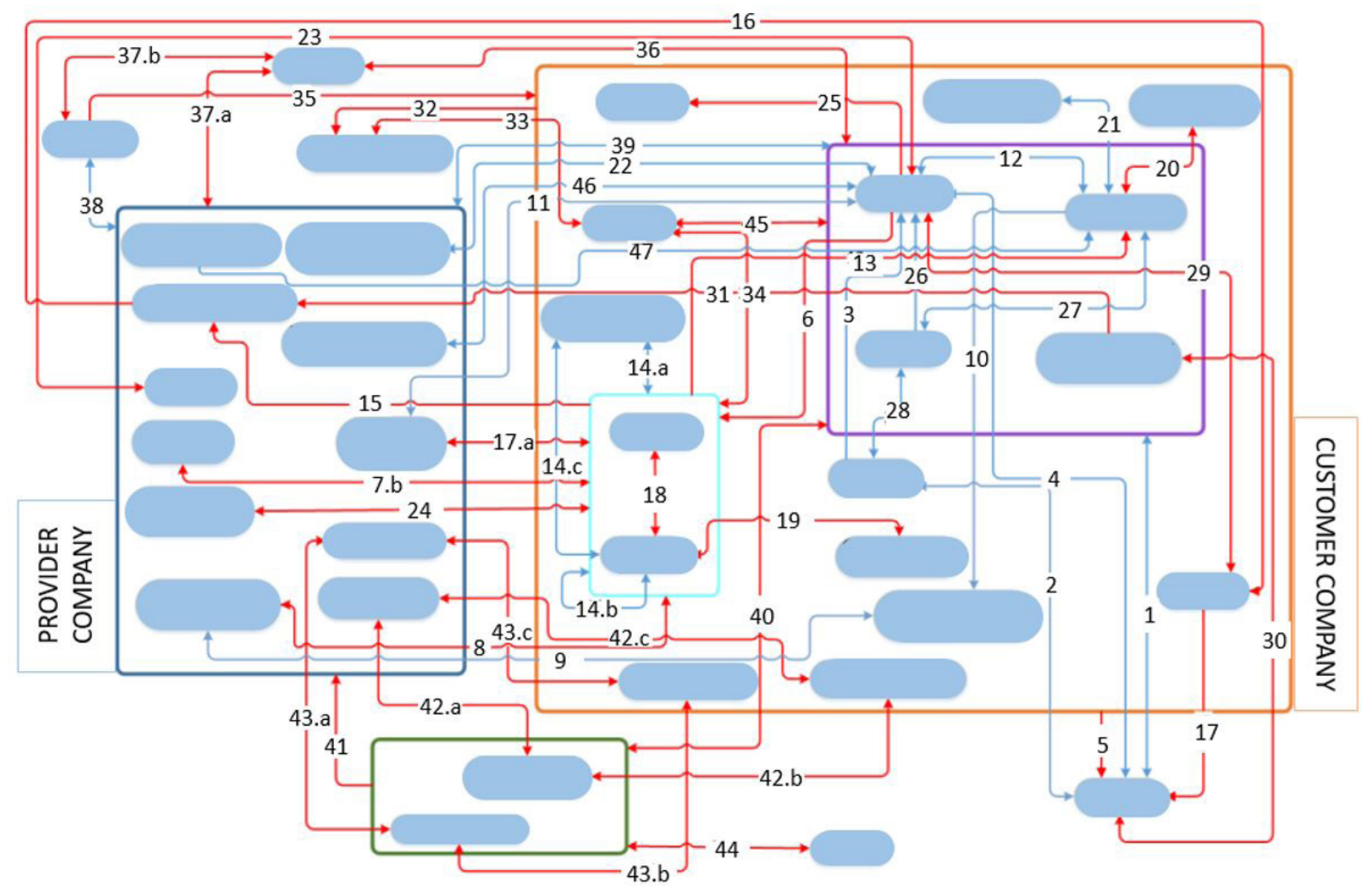

Figure 2. The System Map illustrates what kind of information is transferred between actors.

into categories. It was identified four categories for the first level information and two categories for second level information. In Table 2, technical information represents the most interactions, since the PSS offering development is at the beginning, thus, a technical integration about the platform is required.

In Table 3, the second level information is, basically, about the final customer, since the customer company is still working on its requirements and onboarding them.

Below, Figures 3-5, the information flow for some categories are represented. The thicker lines illustrate the information flows, and it is what differs each figure. It enables to analyse and to identify if some information between actors was omitted and/or to identify the non-optimal distances between them.

Below, the Figure 3 illustrates actors involved in activities related to customer. Many actor exchange information about the final customers' requirements enabling the creation of the roadmap, which is Marketing Department responsibility. The roadmap allows making a long-term planning based on customers' needs. However, the final customers are still being onboarded, which means that the roadmap is in constantly change. Therefore, the exchanged information between actors needs to be correct, since it is important for the customer company to meet their final customers'
Table 2. Categories for the first level information.

\begin{tabular}{|c|c|}
\hline \multicolumn{2}{|c|}{ First level information } \\
\hline Category & Interactions \\
\hline \multirow{2}{*}{ Technical information } & $\begin{array}{r}6,7 . a, 7 . b, 8,13,18,19,20,24,25, \\
34,41,42 . a, 42 . b, 42 . c\end{array}$ \\
\hline Support information & 30,31 \\
\hline Sales information & $5,15,16,17,29,35$ \\
\hline Negotiation Information & $\begin{array}{r}23,32,33,36,37 . a, 37 . b, 40,43 . a, \\
43 . b, 43 . c, 44,45\end{array}$ \\
\hline
\end{tabular}

Table 3. Categories for the second level information.

\begin{tabular}{|c|c|}
\hline \multicolumn{2}{|c|}{ Second level information } \\
\hline Category & Interactions \\
\hline $\begin{array}{c}\text { Information related to } \\
\text { customers }\end{array}$ & $\begin{array}{c}1,2,3,4,9,10,12,21,22,26,27,28,38 \\
39,46,47\end{array}$ \\
\hline $\begin{array}{l}\text { Information related to } \\
\text { possible impacts }\end{array}$ & 11, 14.a, 14.b, 14.c \\
\hline
\end{tabular}

request. When many actors are exchanging the same kind of information, there is a chance of this information being lost or transformed along the way. Therefore, this non-optimal distance between actors can be an obstacle to the customer company in terms of reactivity.

The Figure 4 illustrates actors involved in activities related to technical processes. The same analysis can be done for this information flow: many actors exchanging 


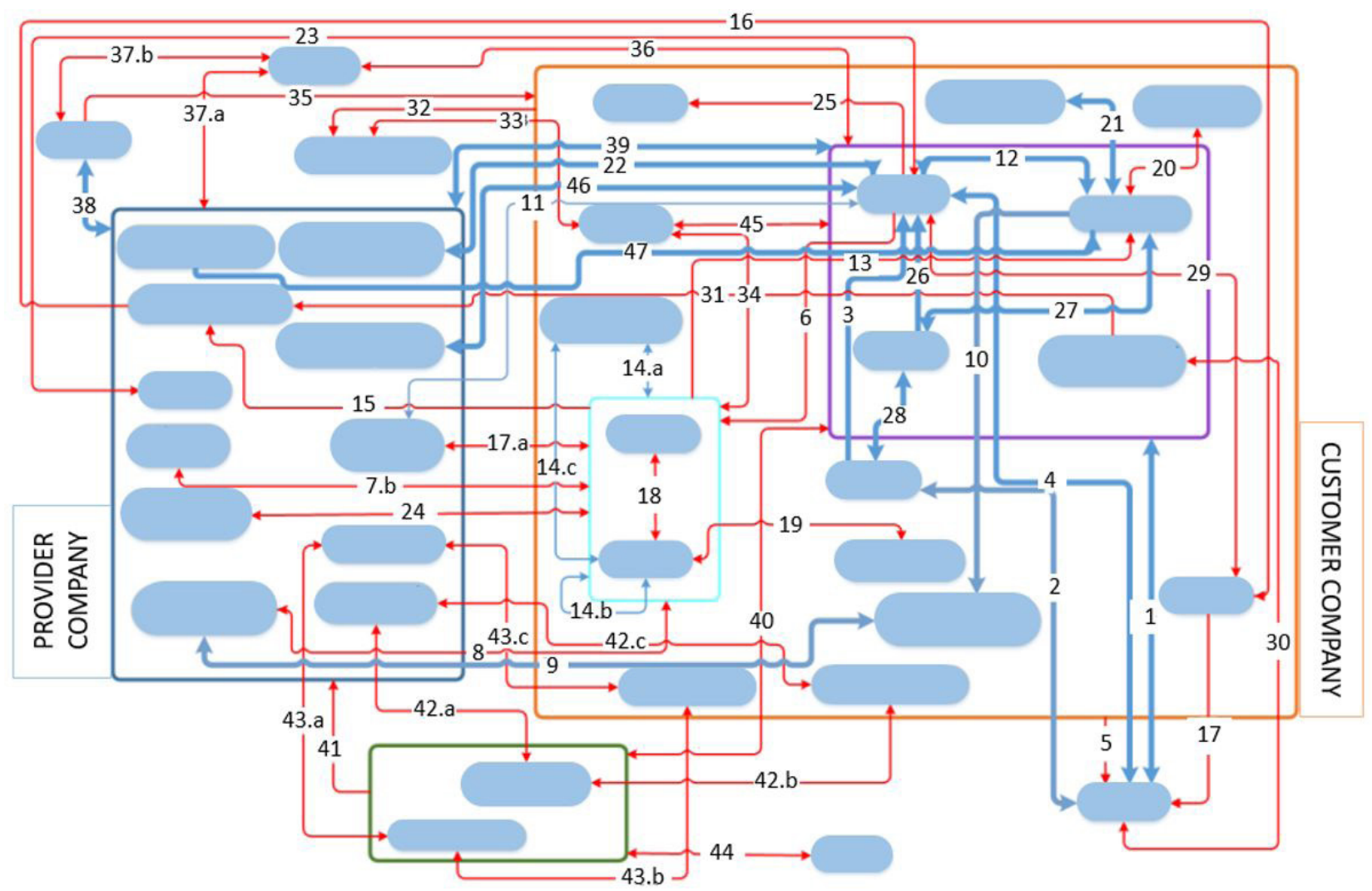

Figure 3. System map that illustrates actors involved in activities related to the final customer.

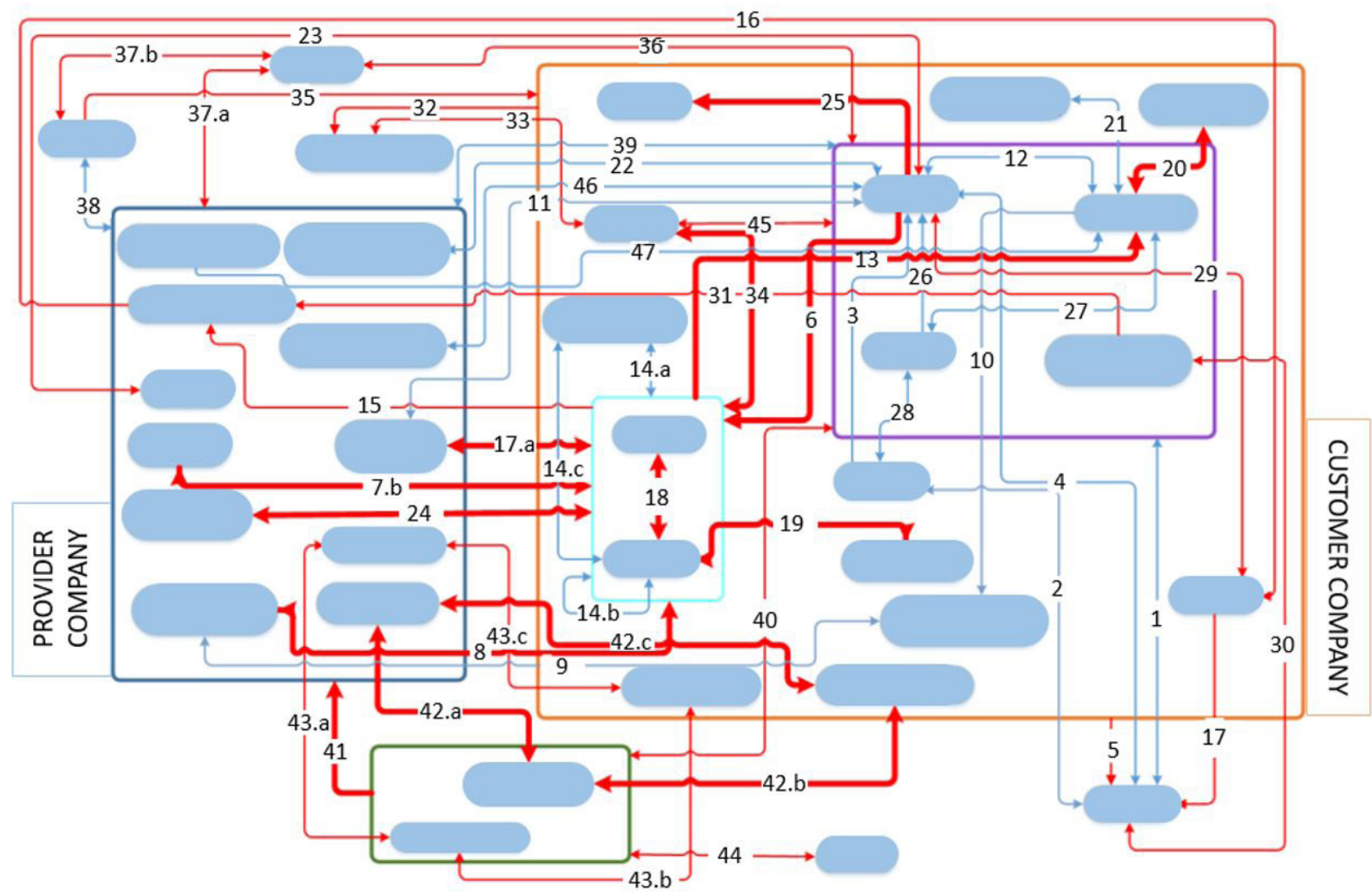

Figure 4. System map that illustrates actors involved in activities related to technical processes. 


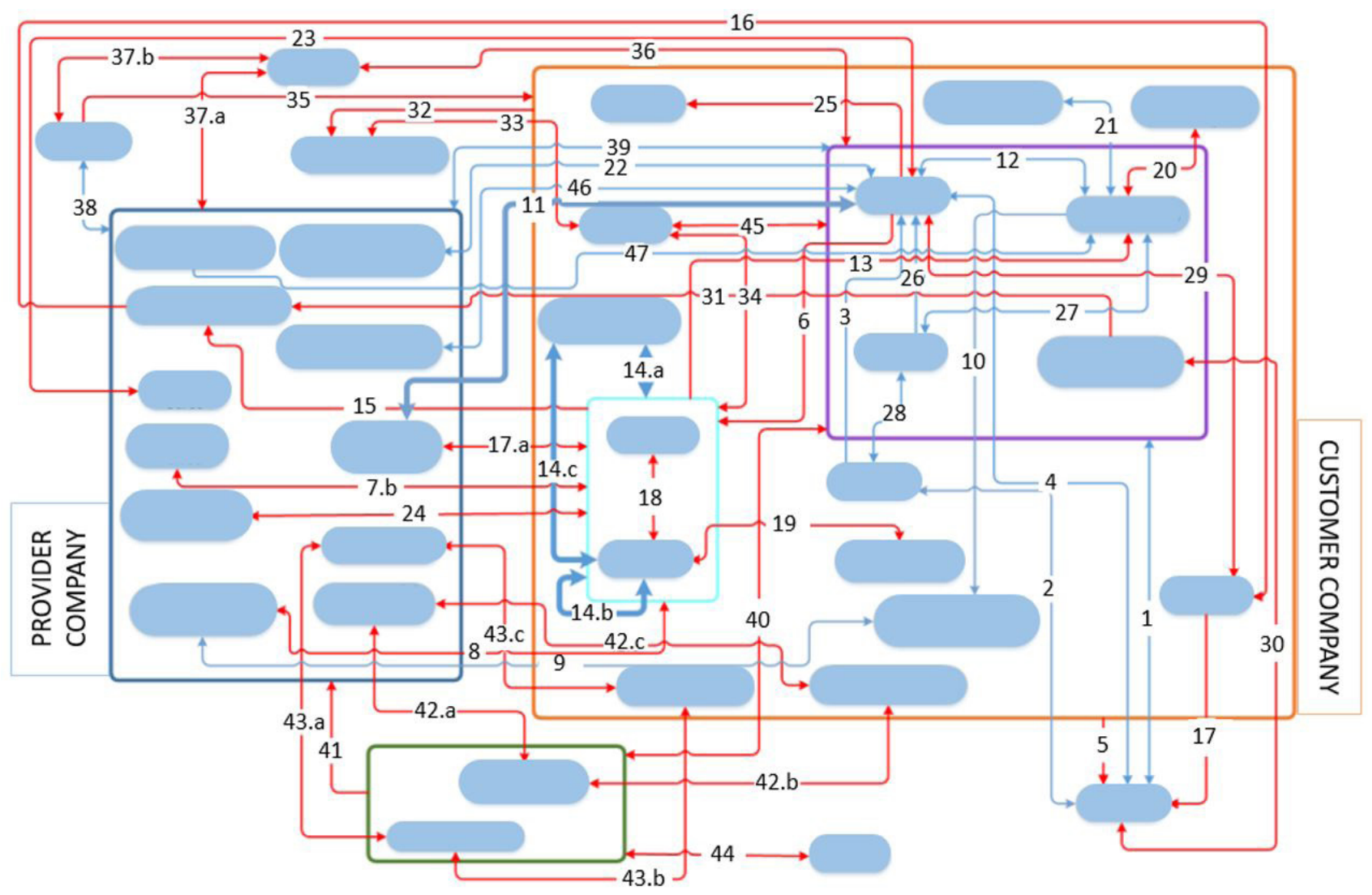

Figure 5. System map that illustrates actors involved in the activities related to possible impacts.

technical information. However, this is a peculiar case. A single actor, Technical Department, is exchanging this type of information with other several actors, which does not communicate between themselves. If these actors also exchange this type of information can be assumed that, probably, Technical Department would not be overloaded with tasks. However, the number of people working within this department is unknown, thus this is just a hypothesis.

The Figure 5 illustrates actors involved in activities related to possible impacts. The interactions $14 \mathrm{a}, 14 \mathrm{~b}$ and $14 \mathrm{c}$ are in a closed-cycle of second level information. An actor from the provider company and Marketing Department are also exchanging such kind of information, interaction 11. However there is no link between all these interactions showing a flow between all these actors. Therefore, it can be assumed that there is information omitted between these actors.

\section{Discussion}

After doing the maps, it is may be noted that they help to identify the actors involved and their interactions in the PSS offering. Hence, the maps help to identify which actor has the most connections, aiding, therefore, in analysing and recognising the importance of that actor, which is line with Tan's (2010) conclusion. The number of connections can signify if the actor is a big one with several people included, who have different tasks, or if the actor that can need assistance given, since it has many connections to other actors (LINDAHL; SAKAO; CARLSSON, 2014). This was observed in Figure 4, where the actor called Technical Department can be overloaded with tasks, since it has many connections, or it can signify that there are many people working within that.

Lindahl, Sakao and Carlsson (2014) also explain that the connections between actors can be long, which can indicate that an actor that possesses important information and an actor that needs to use that information are far from each other and that information can be lost along the way. This was identified in Figure 3, where many actors are exchanging the same kind of information. From the actor that has the information to the actor that needs that information there are many other actors using that information. Thereby, there is a chance of this information being lost or transformed along the way.

It is important that the information follows its normal way to not leave out any actors that are in need of the information. What it could be observed in Figure 5, where there is an omitted information between the actors. Although the information can be omitted or get lost during the way if there are many interactions between actors, not always the 
shortest way is the best one. Few interactions can result in a good exchanged of information between actors, but can also result in actors interested about the information not being informed. When information does not follow the normal flow, going through all actors who need it, this can slows down the PSS development.

Lindahl, Sakao and Carlsson (2014) point out one likely reason for the problems reported above: the respondents had not been fully aware of the actors involved and the system in which their PSS offering are designed and provided.

\section{Conclusions}

This paper presents the understanding of the interaction between actors from a customer company and with external actors, mainly with the provider company, when developing a Product-Service System offering, using a case study of a French telecom company. This study was useful for the participating company, which have realized that there are several issues within their operations that can be improved. Since much data are confidential, some information were not presented in this paper.

In order to the PSS offering to be developed correctly, the actors from customer and provider must have access to important information, must know how this information is transferred, and who will use the information they possess (LINDAHL; SAKAO; CARLSSON, 2014). Therefore, the study identified and analysed, through the Actor's and System Maps, how the actors of the customer company interact with each other and with other actors, especially those of the supplier company. The Actor's and System Map were used as a method to provide an overview of the network of actors in a PSS offering. The Actor's Map (Figure 1), provides an overview of the actors involved in the PSS offering of the case study, showing their main connections and assignments. The System Map (Figure 2) provides a more detailed view of what kind of information is transferred between the actors.

To understand the information flow, categories were developed. Thus, it was possible analysing the information levels and identifying, e.g. omitted information and non-optimal distance between actors.

For further research, other cases could be studied to introduce a perspective of other actors involved in PSSs offerings, which could address a more mature PSS offering. Regarding the map method used, it could be improved and then tested, studying in different kinds of PSSs. Regarding the companies, studying the network of actors they may understand the importance for developing their PSS offerings in a better way when improving their operations.

\section{References}

AURICH, J. C.; FUCHS, C.; WAGENKNECHT, C. Life cycle oriented design of technical Product-Service Systems. Journal of Cleaner Production, v. 14, n. 17, p. 1480-1494, 2006.
BABBIE, E. R. The practice of social research. 13th ed. Belmont: Wadsworth Cengage Learning, 2013.

BEUREN, F. H.; GOMES FERREIRA, M. G.; CAUCHICK MIGUEL, P. A. Product-service systems: A literature review on integrated products and services. Journal of Cleaner Production, v. 47, p. 222-231, 2013.

BRINKMANN, S.; KVALE, S. InterViews: learning the craft of qualitative research interviewing. 3th ed. Los Angeles: Sage Publications, 2015.

BRYMAN, A.; BELL, E. Business research methods. 2nd ed. Oxford: Oxford University Press, 2007.

DONALDSON, K. M.; ISHII, K.; SHEPPARD, S. D. Customer value chain analysis. Research in Engineering Design, v. 16, n. 4, p. 174-183, 2006.

KIMITA, K. et al. Who realizes a PSS?: an organizational framework for PSS development. Procedia CIRP, v. 30, p. 372-377, 2015.

LINDAHL, M.; SAKAO, T.; CARLSSON, E. Actor's and System Maps for integrated product service offerings practical experience from two companies. Procedia CIRP, v. 16, p. 320-325, 2014.

LINDAHL, M.; SAKAO, T.; ÖHRWALL RÖNNBÄCK, A. Business implications of integrated product and service offerings. In: PROCEEDINGS OF THE CIRP INDUSTRIAL PRODUCT-SERVICE SYSTEMS (IPS2), 1., 2009, Cranfield. Proceedings... 2009. Cranfield: Cranfield University. p. 165-172.

MANZINI, E.; COLLINA, L.; EVANS, S. Solution oriented partnership: how to design industrialised sustainable solutions. Cranfield: Cranfield University, 2004.

MATZEN, D. A systematic approach to service oriented product development. Denmark: DTU Management Engineering, 2009.

MONT, O. Clarifying the concept of product-service system. Journal of Cleaner Production, v. 10, n. 3, p. 237-245, 2002.

MORITZ, S. Service design - practical access to an evolving field. Germany: International School of Design, University of Applied Sciences Cologne, 2005.

ROSE, C. M.; STEVELS, A. Applying environmental value chain analysis to product take-back systems. In: LIFE CYCLE ENGINEERING CONFERENCE, 7., 2000, Tokyo, Japan. Proceedings... 2000. IEEE, p. 38-45.

SONG, W. et al. An integrative framework for innovation management of product-service system. International Journal of Production Research, v. 53, n. 8, p. 2252$2268,2015$. 
TAN, A. R. Service-oriented product development strategies. Bygning: Danmarks Tekniske Universitet, DTU Management Engineering, 2010.

VASANTHA, G. V. A. et al. A review of product-service systems design methodologies. Journal of Engineering Design, v. 23, n. 9, p. 635-659, 2012.

WEEKS, R.; BENADE, S. Servitization: an integrated strategic and operational systems framework. In:
PORTLAND INTERNATIONAL CONFERENCE ON MANAGEMENT OF ENGINEERING AND TECHNOLOGY (PICMET), 2014, Kanazawa, Japan.

Proceedings... USA: IEEE, 2014. p. 3272-3280.

ZINE, P. U. et al. A framework for value co-creation through customization and personalization in the context of machine tool PSS. Procedia CIRP, v. 16, p. 32-37, 2014. 